\title{
Performance, Programa e Cidade: Urbanismos do Chão
}

\author{
Bárbara Silva da Veiga Cabral \\ Urbanista-performer. Mestra pelo Programa de Pós-Graduação em Artes da Cena da UFRJ. \\ ORCID iD 0000-0002-7172-8969 \\ Contato: barbara.svcabral@gmail.com
}

\begin{abstract}
RESUMO
Articulando práticas artísticas e urbanísticas ao trabalho de autoras dos campos da dança, filosofia, performance e urbanismo, o artigo tem como ponto de partida revisar a colocação de Hannah Arendt (2007)e André Lepecki (2012) de que a arquitetura (o fazer cidade) é fundamentalmente anterior à política (agir cidade). A revisão parte de uma experiência que vivi em TECIDO-NÃO-TECIDO (2018), performance realizada na Barra da Tijuca. O contraponto que a performance traz é matéria para expandir as noções de política e arquitetura - reforçando que agir cidade é, de fato, fazê-la. Ao pensar arquitetura e urbanismo enquanto "políticas do chão" (CARTER, 1996), o texto termina com um breve ensaio sobre a palavra programa, comum aos campos da arquitetura e da performance, e propõe uma espécie de urbanismo imanente e do chão, cujo operador é o "programa performativo" (FABIÃO, 2013), enunciado conciso de performances, de modo a subverter a frequente determinação de usos em arquitetura e urbanismo via programas funcionais.
\end{abstract}

Palavras-chave: Performance; Cidade; Arquitetura e Urbanismo; Programa performativo; Chão.

\section{Performance, Program and City: Urbanisms of the Ground}

\begin{abstract}
By articulating artistic and urbanistic practices with the work of authors from the fields of dance, philosophy, performance and urbanism, the article's starting point is to review Hannah Arendt's (2007) and André Lepecki's (2012) statement that architecture (to make the city) is fundamentally prior to politics (to act the city). This review is based on an experience I have lived in TECIDO-NÃO-TECIDO (2018), a performance art piece held in Barra da Tijuca, Rio de Janeiro. The counterpoint that this performance brings is used as a material to expand the notions of politics and architecture - reinforcing that acting the city is, in fact, making it. Thinking about architecture and urbanism as "ground politics" (CARTER, 1996), the text ends with a brief essay on the word program, common to the fields of architecture and performance art, and proposes a kind of immanent and ground urbanism, whose operator is the "performative program" (FABIÃO, 2013) - subverting the frequent determination of uses in architecture and urbanism via functional programs.
\end{abstract}

Keywords: Performance; City; Architecture and Urbanism; Performative program; Ground. 


\section{Política-Pólis-Performance}

Começo por contar que, entre março e julho de 2019, no início de todas as minhas tardes de quinta feira, presenciei a construção de espaços por palavras. Sim, palavras. Destas ditas, saídas das bocas, num misto de vento, silêncio, língua, vibração e som. Explico: como exercício proposto por Eleonora Fabião, em disciplina do mestrado em artes da cena da UFRJ, líamos uma série de textos e separávamos, para cada aula, algumas epígrafes que nos interessassem. E, então, cada qual lia as citações que havia escolhido, sem ordem pré-estabelecida, seguindo o desejo da mente e do corpo de falar.

Sem entender muito como, eu, arquiteta e urbanista recém-formada e recém-lançada à performance, deixava a sala de aula impressionada. A sensação, no ato e na memória, era mesmo essa: a de que estávamos construindo ali, por meio de nossas interações e composições de relevos entre ideias, vozes e temas distintos, uma espacialidade diversa. Um espaço suspenso em temporalidades breves e sustentado por palavras, no lugar - ou para além - de paredes. Por relações e durações. Assemblar efêmeros enquanto operação espacial.

Lembro-me do trabalho Six blown lines (1970), de Barry Le Va. O artista dispunha cuidadosamente, uma a uma, seis longas linhas de farinha sobre um chão de madeira e, depois, as soprava lateralmente com um compressor de ar - até que a superfície da sala restasse basicamente coberta. As fileiras de pó recuadas pelo vento, a sobreposição de resíduos: novos relevos estabelecidos pela obra - dialética entre matérias e manipulação. ${ }^{1}$ As inter-relações e ativações, momentâneas como um sopro, conformando chão. Exemplo um pouco mais concreto, ainda que não experimentado, de criação de espaçocorpo por meio de brevidades.

Digo espaçocorpo, pois que, como nos conta Gilles Deleuze a partir de Espinosa: "Um corpo pode ser qualquer coisa, pode ser um animal, pode ser um corpo sonoro [como no primeiro exemplo], [...] uma coletividade" (DELEUZE, 2002, p. 132) - sendo definido pelos encontros e afetos que é capaz de gerar e gerir e por suas velocidades e lentidões. Neste sentido e segundo o que entendo, espaço é também corpo. Afeta e se afeta conosco. Compõe-se e decompõe-se das relações que o atravessam. $\mathrm{E}$ das brevidades de que falo, ações efêmeras, também.

Sobre elas, gostaria de trazer um texto - e alguns caminhos. Em Coreopolitica e Coreopolícia (2012) e em conversa com escritos de Hannah Arendt (2007), Giorgio Agamben (2008) e Jacques Rancière (2010), o professor e teórico da dança André Lepecki realiza uma aproximação entre artes efêmeras e política. Conta-nos dessa política que, à diferença da politicagem, é feita a cada ação, contextualmente, e cujo produto é o próprio processo.

Uma política que se aproximaria de artes como a dança, o teatro e a performance por seu âmago estético, instável, agente e dissensual. Definida em termos estéticos por intervir no "visível e no dizível” (RANCIÈRE apud LEPECKI, 2012, p. 43) e fundamentada no dissenso ao romper com "hábitos [...] e clichês que empobrecem a vida e seus afetos" (LEPECKI, 2012, p. 44), a verdadeira política seria aquela responsável por uma "abertura de potências" (AGAMBEN apud LEPECKI, 2012, p. 44), praticada em um campo sempre provisório de disputa e diferença.

Política, como dança, teorizando - no ato - o contexto social a partir do qual e sobre o qual se move. Efêmera, precária, processual. Política, como performance, agenciando e (re)fazendo corpo com.

Mas se aqui o produto da ação é o próprio processo, qual a relação entre epígrafes, linhas sopradas, política, arquitetura, urbanismo e cidade? Penso, primeiro, nas configurações espaciais que as ações políticas - enquanto atividades performativas, dissensuais e sempre à beira de seu próprio desaparecimento - instauram, ainda que momentaneamente. Aí onde vocábulos compõem corpo sonoro espacial, afetante e afetado, modulado cinética e dinamicamente. Em sequência, busco considerar as implicações de ações efêmeras para além de suas durações. O que mobilizam e conformam, os afetos que instauram e, mais além, as possíveis relações entre política e arquitetura. Política e cidade.

Se com as epígrafes a espacialidade é suspensa em sua própria temporalidade breve, perdurando no corpo enquanto memória, com a farinha e o vento, os efeitos das condições de campo ali criadas, também a partir de efemeridades, tornam-se mais sólidos. Pergunto-me: que marcas deixam os gestos mínimos? Que espaços configuram?

Demos um passo - atrás. Nesse mesmo texto e a partir de Arendt, Lepecki aponta o urbano contemporâneo como espaço construído por tangíveis imóveis, "suporte material necessário para conter a efemeridade, a precariedade, o deslimite e a imprevisibilidade ontológica da política" (LEPECKI, 2012, p. 48). Nessa perspectiva, projeto e construção de espaço urbano aparecem como fabricação necessária e ante-

Revista online do Departamento de Arquitetura e Urbanismo da 
rior à ação - ou seja, como atividade produtiva "que precede a política e lhe dá chão” (LEPECKI, 2012, p. 48).

Enquanto a fabricação é definida por Hannah Arendt como atividade de produção, "um meio de produzir um objeto" (ARENDT, 2007, p. 193), seja ele de uso ou mesmo uma obra de arte, a ação é puro instante intangível - termina quando as atividades são suspensas. Desse modo, se a fabricação pressupõe meios para atingir fins ou realizar feitos pensados a priori, ou seja, projetados para existirem como obras autônomas de quem os cria (mesas, prédios, cadeiras, calçadas, quadros, praças), as ações políticas - como toda ação - operam de outra maneira: como eventos, se dão entre as pessoas, tendo como produto o próprio processo.

A separação radical que Arendt realiza entre ação e fabricação é, ainda, conforme indica Lepecki, uma diferença fundamental entre agir (verbo ligado à verdadeira ação política) e fazer (da ordem da fabricação) - e, em última instância, entre ação política e espaço urbano, experimentação e projeto, performance e cidade. Nesse sentido e partindo do que a autora nomeia como "a solução grega original e pré-filosófica" para a fragilidade da ação ${ }^{2}$ - nomeadamente: a constituição formal da pólis, sua fabricação - Lepecki lê a cidade contemporânea.

Coloca que a arquitetura - o fazer cidade - é fundamentalmente anterior à ação política - agir cidade. Nessa perspectiva, há sempre um "chão urbano" antecedente que propicia os encontros. Perceber uma anterioridade da fabricação urbana em relação à ação política é compreensível, afinal, conforme defende Arendt, a solução da construção da pólis grega fundou o imaginário e a organização política ocidental; é preciso ter/fazer um espaço onde agir. Uma experiência que vivi nos chãos da Barra da Tijuca, no entanto, me leva a pensar de outro modo - embaralhando categorias, borrando separações. Entre agir e fazer, política e projeto, performance e cidade: TECIDO-NÃO-TECIDO.

\section{Panos e Pregos: práticas de chão}

Em 20 de junho de 2018, TECIDO-NÃO-TECIDO acontece. Ressoando no corpo, o programa da ação: cobrir, com tapetes vermelhos, caminhos - percursos marcados pelo caminhar de corpos em solo urbano. Mais especificamente: entapetar trilhas abertas por pés em gramados íngremes, situados entre vias expressas, na desembocadura de duas pontes paralelas batizadas Lucio Costa e Oscar Niemeyer. ${ }^{3}$ Barra da Tijuca, Rio de Janeiro: bairro cuja urbanização modernista, baseada no Plano Piloto (1995) de Lucio Costa, privilegia uma automobilidade sobre rodas.

TECIDO-NÃO-TECIDO consistia, então, em cobrir com tapetes vermelhos esses caminhos de terra (também vermelha) abertos na grama verde por passos cotidianos que, por desejo ou necessidade, criam passagens para além das oferecidas pela estrutura urbana funcional, lucrativa e moderna. Assim, ao agir o programa na manhã do 20 de junho com outras quatro mãos parceiras,${ }^{4}$ desenrolei e fixei com pregos, sobre os caminhos já abertos, centenas de metros de TNT vermelho.

TNT (sigla para tecido não tecido) é o nome dado ao material agenciado nessa experimentação - semelhante a tecido, mas obtido por prensa de fibras e polímeros. Vendido a metro no Saara ${ }^{5}$ e em lojas especializadas em diferentes cores e gramaturas, o TNT é amplamente conhecido. Matéria de baixo custo, fina, porosa, biodegradável e largamente utilizada (de decorações de festinhas e trabalhos de escola à forração de móveis de luxo), , aqui, é também o tecido-não-tecido do projeto urbano - malha urbana não desenhada por urbanistas, mas sim pela prática de corpos nos vaivéns cotidianos.

Marcas no chão que, enquanto para o urbanismo francês são "linhas do desejo" (lignes de désir), no vulgo brasiliense são conhecidas como caminhos de rato $^{6}-$ mamífero desprezado em ambientes urbanos, associado a esgotos, doenças e mundos subterrâneos. A relação, que acontece porque os roedores deixam traçados seus percursos em vegetações herbáceas, evoca, ainda, nas cidades, o desprezo de determinados projetos urbanos aos corpos caminhantes.

Nesse sentido, agir TECIDO-NÃO-TECIDO consistiu em oferecer tapetes vermelhos aos caminhos de rato como quem entapeta cerimônias luxuosas, desfiles e premiações. Estender tapetes de TNT vermelho e popular para que os corpos caminhantes pisem. Pregar panos no chão como quem deita bandeiras vermelhas às trabalhadoras e trabalhadores que por ali passam. Ou como quem expõe chagas, demarca veias e sangues derramados. Rastreia rasgos na terra, cicatrizes do chão brasil. Vermelha é também a tinta da caneta que corrige o que falha - esse desenho urbano nos falha. Uma tinta-tecido-não-tecido que reforça o traço dos pés no chão.

Curioso pensar que, à diferença de tecidos convencionais, compostos por malhas ortogonais ou ordenadas, a trama do TNT quando vista no microscópio é multidirecional, como as trilhas abertas no gramado - característica curiosa da

Revista online do Departamento de Arquitetura e Urbanismo da 


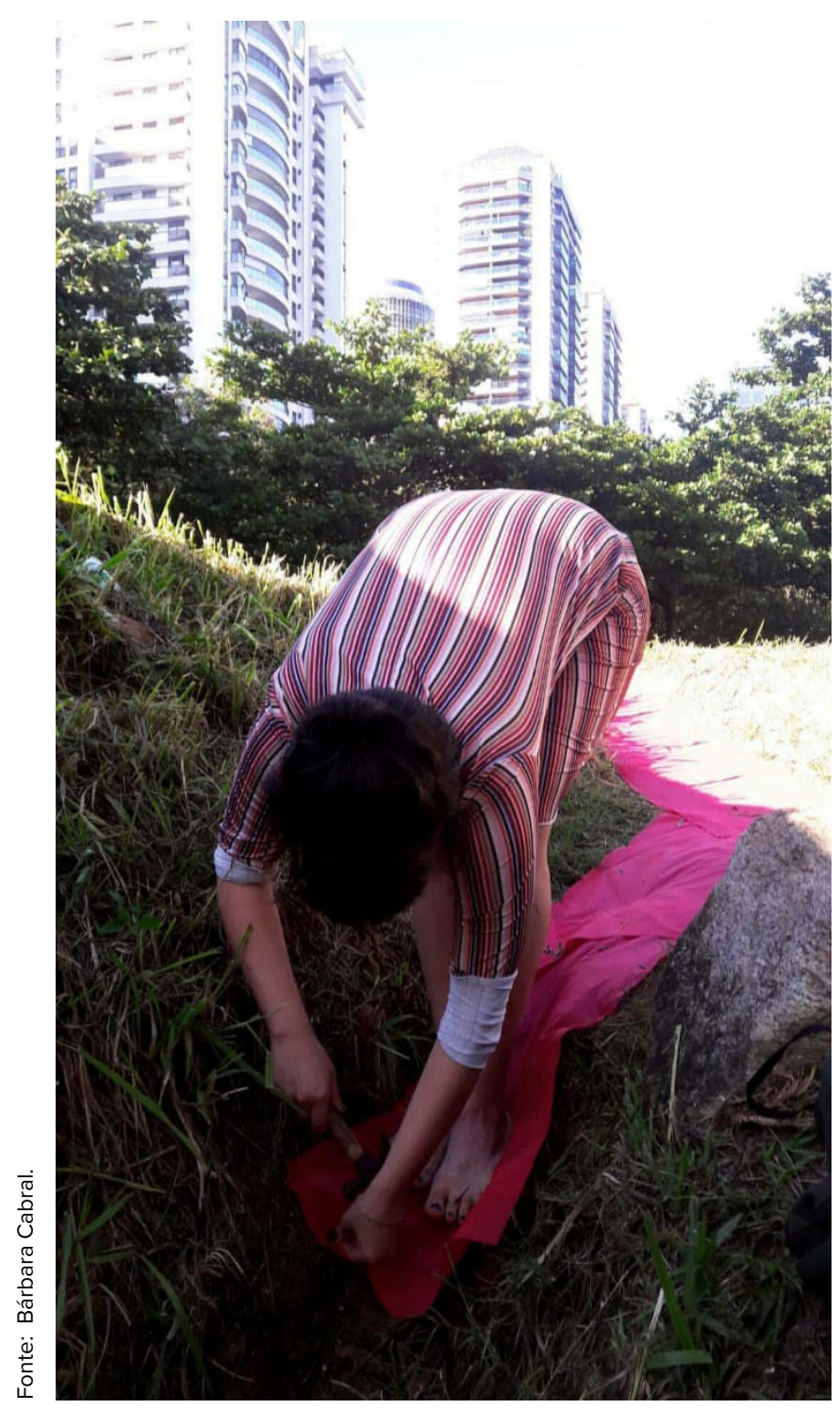

Figura 1. TECIDO-NÃO-TECIDO, 2018.

matéria, significativa para o trabalho. Do mesmo modo, enquanto o urbano planejado e construído da Barra da Tijuca é ordenado feito tecido (trama urbana fabricada que privilegia uma automobilidade eficiente e motorizada), os caminhos abertos por nossos pés (terra batida pelos passos) desenham outro tipo de espaço, determinado pelas iniciativas dos corpos caminhantes.

É na contramão desse fazer urbano ordenado que corpos indisciplinados perfuram a lógica espacial estabelecida e instauram outra (uma corpográfica), desenhando novos trajetos, abrindo caminhos, instaurando dissenso pela caminhada. Nesse dia, um deles se aproxima e me conta histórias, enquanto eu, sentada no chão, bato martelos e furo panos e terras. É uma mulher. Ela me diz, entre outras coisas (os olhos cheios d'água), uma frase que ressoa ainda: "Eu faço esse caminho há doze anos".

Com licença, qual o propósito disso? [...] Percebi que era uma demarcação em vermelho, mas não sabia o porquê. Achei muito interessante. [...] Esses caminhos têm muita história. Já vi muita gente chorar aqui, muita gente rir, se abraçar, brigar, já fiz amigos e já consolei pessoas que nem conhecia, que precisavam de um apoio. [...] Esses caminhos têm muita história. Histórias que muita gente não sabe, talvez nem vocês saibam. Achei muito bonito isso que vocês estão fazendo, mexeu com meu emocional. [...] Eu faço esse caminho há 12 anos. (CABRAL, 2018, p. 77-78)

Doze anos. Pergunto o que ela vem fazer ali há 12 anos. Trabalho. "Sou empregada doméstica no Atlântico Sul" um dos primeiros e mais caros condomínios da Barra da Tijuca. Me diz que sai às cinco, quem sabe nos vemos, que Deus nos abençoe, e segue seu caminho. Seu caminho. Repito porque acho que vale, sinto que devo: Eu faço esse caminho há 12 anos. Ela faz o caminho. Nos dois sentidos: da passagem à construção. Caminha o caminho e o caminho é porque ela - e os tantos outros corpos que com ela vão caminha.

A ação do caminhar, aqui, enquanto construção de espaço urbano, de espaçocorpo, de corpo-cidade. Uma feitura de cidade que passa pelos passos. Pelos gestos mínimos e cotidianos. Ações. Uma feitura de cidade, enfim, política. Ou ainda: um agir que faz, concretamente, o urbano. Vozes e passos que, disparados por uma proposição performativa, expandiram em mim as noções de política e arquitetura que compartilho agora - reforçando que agir cidade é, de fato, fazê-la.

A partir desse encontro passo a entender arquitetura e política, urbanismo e ação, enquanto atividades coconstitutivas e concomitantes, no lugar de sequenciais. É no espaço proibido e "impróprio para pedestres", nesse chão difícil, íngreme e não pavimentado, que a política entre pés e chão acontece - agenciamento de efêmeros que conforma percursos. Contra a determinação do projeto urbano, a fazeção de cidade - fazer e agir conjuntos, construindo espaço na medida em que o praticam. 


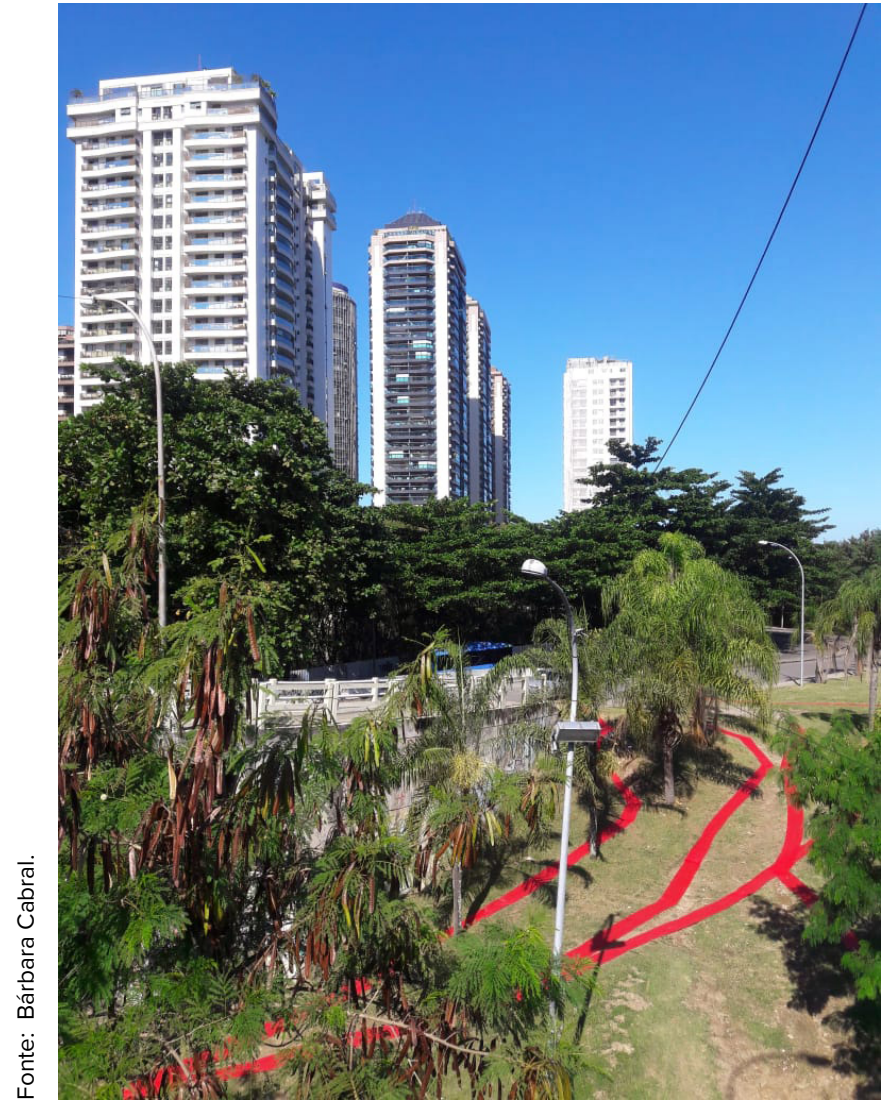

Figura 2. TECIDO-NÃO-TECIDO, 2018.

De fato, práticas cotidianas como esse caminhar borram os limites entre as categorias de ação e fabricação definidas por Arendt e ensinam que há outros modos de pensar, projetar e viver cidade. Embaralhamentos que, para além dos realizados e pensados por proposições artísticas, estão presentes já na vida cotidiana. Vale dizer que o pensamento que separa arquitetura de ação, para além de defendido por Arendt, é senso comum, inclusive na academia, em disciplinas de arquitetura e urbanismo que me formaram. Usual pensar que arquitetura e urbanismo são a fabricação desse espaço, sua predeterminação; enquanto a ação, uso e experiência dos espaços são coisa à parte e posterior. Embaralhar categorias, portanto, abre potência para pensamentos de projeto e práticas de construção urbana menos utilitárias e predeterminadas, feitas mais a partir de encontros, afetos e políticas que de formatos e funcionalizações.

Nesse sentido, para além de pensar o urbanismo anterior, que orienta usos e espaços atualizados pelos corpos em experiência, me interessa buscar agir urbanismos que não propõem soluções e previsões, mas conversas, no aqui e agora, com as políticas e matérias existentes. Urbanismos performativos, da ação.

Se insisto no termo urbanismo, é em disputa pelas palavras que, sabemos, não são fixas ou neutras. ${ }^{7}$ Nomear urbanismos o que faço me parece importante na defesa de um campo aberto, em constante refazimento e desprogramação. Urbanismos performativos, da ação, mobilizam os campos convocados em experiências transdisciplinares e críticas porque sempre apoiadas em chãos instáveis (repletos das mais variadas forças e matérias).

É em oposição à tendência geral do urbanismo acadêmico e profissional - uma tendência-herança baseada na "história oficial" do movimento moderno que, como define a pesquisadora e professora Paola Berenstein Jacques, está calcada no "mito do progresso, do desenvolvimento técnico acrítico e do excesso funcionalista que está na base da emergência da própria disciplina do urbanismo (criada para ordenar o crescente 'caos' urbano no século XIX)” (JACQUES, 2018, p. 19) - e em alternativa a práticas pouco implicadas com os processos, corpos e contextos já existentes nas cidades, que me interessam as fazeções de urbanismos performativos, da ação.

Urbanismos que, de partida, solicitam o que propõe Jacques (2009, p. 115): uma "co-implicação direta entre corpo e cidade, e que poderia vir a ser a base de uma prática de urbanismo mais “incorporada'”. Assim, é habitando o paradoxo entre projeto e prática/construção e como urbanista-performer, que arrisco experimentar urbanismos da ação inventados a cada novo programa que elaboro - plurais porque não se querem como modo único de fazer, ou modelo de fabrica-

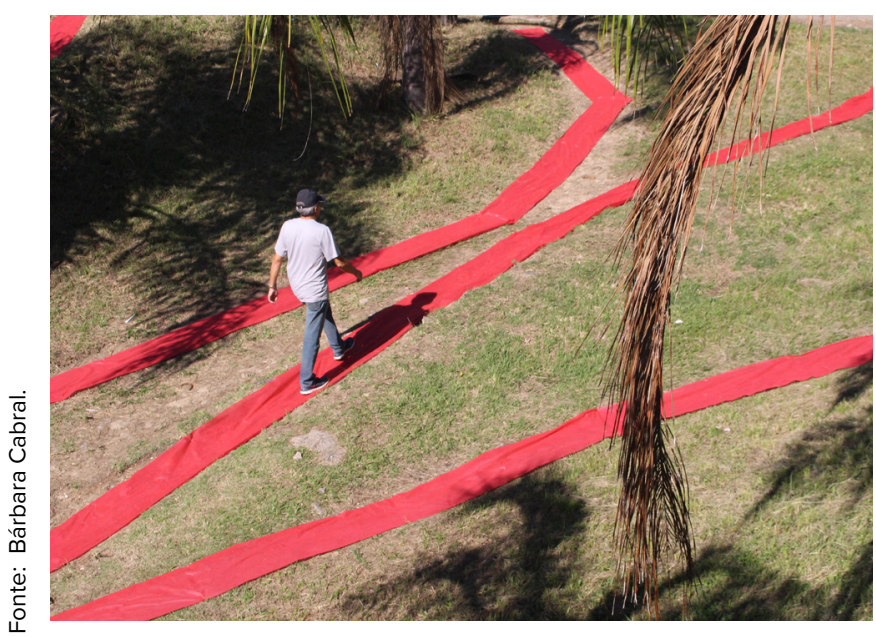

Figura 3. TECIDO-NÃO-TECIDO, 2018. 
ção, "da ação" porque implicados em práticas cotidianas e efêmeras que constituem cidade; políticas urbanas.

Da proximidade entre dança, política e esses urbanismos da ação e das reflexões provenientes da experimentação dos tapetes me interessa, ainda, pensar arquitetura e urbanismo enquanto políticas do chão. Conforme define Lepecki (2012, p. 47) a partir de Paul Carter, uma política do chão é nada mais, nada menos que "um atentar agudo às particularidades físicas de todos os elementos de uma situação, sabendo que essas particularidades se coformatam num plano de composição entre corpo e chão chamado história" - e, penso eu, chamado também: cidade.

Nesse sentido, tenho como partido projetar-agir em atenção aos afetos, corpos, gestualidades e ações cotidianas. Em atenção às materialidades, durações e aos rastros que corporificam. Operar a partir das matérias, forças e potências urbanas presentes já. Dos fluxos e encontros que nos compõem como corpo-cidade. Em conversa com as práticas dos chãos do urbano, experimentar fazeções.

\section{Planos e Pisos: imanência e experimentação}

Enquanto escrevo estas linhas, as viaturas da nova cidade ${ }^{8}$ já fizeram suas passagens, vejo da janela de casa. Viaturas que abrem o caminho para as outras todas e afirmam o espetáculo urbano da circulação e uso disciplinados. Do suposto chão liso e neutro que agora soterra os caminhos antes marcados em vermelho e os pregos da ação, ignorando o que há anos os corpos caminhantes andam fazendo.

Retroescavadeiras, pás carregadeiras, rolos compressores, caminhões... Obra recém começada, resultada do atrito público-privado: um homem quer seu terreno de volta e para isso é preciso passar por cima. Garante-se, no entanto, a livre circulação dos veículos. A mobilização de terras, máquinas, corpos, enfim, é imensa. Imagem: afirmação do projeto urbano que não passa pela fazeção de cidade, que constrói todos os melhores atalhos e vias para os automóveis, ignorando fluxos e forças operantes que rompem com os limites por ele estabelecidos. Passando por cima.

Da mesma janela, vejo três pontos que agitam um quarto, menor. Durante a obra da via, três pessoas jogam uma altinha. Meio da rua. A bola de futebol entre o chão proibido - ou suspenso - e o ar; dissenso e coreopolítica se fazendo ao vivo. Corpos que insistem em agir e fazer cidade, sobre os escombros daquela outra, recém soterrada pelas viaturas do novo projeto. Entre os alisamentos do chão urbano - que sempre, sempre racha -, seguem os quatro seus caminhos em direção à praia e fico eu, pensando: como seriam urbanismos que assemblam esses efêmeros? Quais as faces, ou, talvez mais importante, quais os processos dessa outra cidade?

Interessa-me considerar práticas cotidianas - essas que rompem com lógicas espetaculares ou determinadas - enquanto feituras de cidade. Projetar a partir delas. Nesse sentido, lembro-me de uma frase anotada em um caderno de 2017 enquanto lia Condições de Campo do arquiteto e teórico Stan Allen. Busquei a frase no texto e não estava. Parece ser da ordem do que ressoa no corpo na duração da leitura: "ação é arquitetura".

Há ações que são e fazem, de fato, arquitetura, cidade. Movimentos que, interessados no deslocar-se, desenham e constroem espaço. E a iniciativa dos corpos enquanto disparador da fazeção. Como em Park Fiction, outra nota em cadernos. Um parque construído em St. Pauli, distrito da luz vermelha de Hamburgo, Alemanha, planejado pela vizinhança. Possibilitado pelas chamadas Produções Coletivas de Desejos, ali organizadas desde 1995, e localizado em zona portuária ameaçada à época de ser vendida pelo governo a investidores privados, o parque que hoje existe foi projetado pelos moradores - sendo inaugurado em 2005, após dez anos de lutas.

Uma rede inteligente se formou na comunidade, organizando um Processo de Planejamento Paralelo para a área, que funcionava como um jogo e estabelecia trocas entre residentes de diferentes campos e produções - músicos, crianças, artistas, cozinheiro, psicóloga, sacerdotes, donas de cafés etc. Por meio de ferramentas especiais que acessibilizavam o planejamento - como um Arquivo de Desejos, o Kit de Ação portátil e uma linha telefônica para receber chamadas de pessoas que tivessem inspirações noturnas - , as ideias foram sendo colocadas e posteriormente transformadas em projetos edificáveis por residentes e pela Park Fiction em colaboração com paisagistas.

O processo incluía palestras, filmes e debates ao ar livre sobre política, espaço público e suas relações (nomeado Infotenimento); a distribuição de tabuleiros de jogo (e não de panfletos) que mostravam os pontos de acesso ao processo de planejamento; visitas a residentes com o Kit de Ação portátil (uma maleta com plantas baixas, questionários, um panorama do porto, massinha de modelar, lápis, uma câmera instantânea "para capturar ideias" e um gravador de fita cassete); uma biblioteca no jardim, mesas e materiais 
de desenho; e um contêiner que abrigava oficinas, o Arquivo de Desejos e a caixa postal da linha telefônica noturna. A vizinhança desenvolveu um conceito de parque a partir dos desejos existentes - um processo de planejamento paralelo e acessível "conectando artes e movimentos sociais sem cair na armadilha de seguir o caminho 'legal' de participação limitada do sistema burocrático [...], desafiando o sistema dominante de planejamento urbano" (SCHÄFER, 2004, on-line, tradução própria).

No parque, inspirado na teoria do Direito à Cidade de Henry Lefebvre (2011) encontramos, por exemplo: uma Ilha de Palmeiras (gramado circular, rodeado por um banco, com duas palmeiras artificiais baseadas em um desenho feito em 1997 por um menino chamado Yusuf), um Tapete Voador (topografia ondulada e gramada, com mosaicos nas bordas, inspirados na Alhambra, Espanha), um campo estampado com tulipas (projetado por uma vizinha turca em referência a uma época de florescimento artístico e tolerância na Turquia do século XVI), e um Jardim de Cachorro (onde cresce uma árvore podada em formato de poodle). Há ainda o que construir por falta de financiamento - o que representa, segundo o site ${ }^{9}$ do parque, o dano que acontece aos desejos quando envolvidos em burocracias. Inaugurado com um Piquenique Contra a Gentrificação, o parque foi renomeado em 2013 como Gezi Park Fiction, em solidariedade às lutas de Istambul e contra o esvaziamento, por operação militar truculenta, da ocupação Gezi, na Turquia - país em que alguns dos vizinhos nasceram.

Produções coletivas de desejos, kits de ação, jogo, lutas, colaboração: procedimentos, arrisco, de um possível urbanismo incorporado e político. Do chão porque atento às materialidades e desejos que se coformatam no plano de composição da cidade, e que incluem os corpos tantos. Exemplos de "como as pessoas podem se firmar no terreno escorregadio do pós-fordismo, conectando lutas espaciais” (PARK FICTION, 2013, on-line). Mais que ferramentas, entendo, os procedimentos são a própria cadência da construção do parque, ritmo de um processo: uma dança, que, enquanto "teoria social da ação" - posto que sobre ela se debruça, ao refletir agenciamentos sociais - é "também teoria social em ação" (LEPECKI, 2012, p. 45) - a vizinhança dançando o projeto, em experiência e concepção.

Nos caminhos de uma cidade plano de composição aposta minha a partir da ideia de Paul Carter de uma história que se faz "entre corpo e chão" (LEPECKI, 2012, p. 47) e que relaciono aos pensamentos de Deleuze e Félix Guattari (2012a, p. 36), que definem o plano de composição ou de consistência em oposição ao de organização e formação ${ }^{10}$ arrisco, ainda: obrar cidade enquanto campo imanente do desejo - que não é falta, é produção.

Conforme evocam os filósofos, o plano de consistência próprio do desejo, "construído pedaço a pedaço", seria composto de corpos-passagens e regiões de intensidade contínua, sempre em fluxo (DELEUZE e GUATTARI, 2012b, p. 22, 25 e 27). Sua imanência (qualidade daquilo que lhe é inerente e substancial, não transcendente) no desejo se justifica porque é dele e a partir dele que o plano se faz. E, sendo assim, nele, o que acontece são experimentações desejantes.

Dessas propostas, traço por horizonte: pensar cidade como plano de consistência - cuja operação é a experimentação. ${ }^{11} \mathrm{E}$ se, a partir de Carter, compreendo cidade como o plano de composição entre corpo e chão: interessa fazê-la por meio do que imana de desejo desta relação - políticas imanentes do chão do urbano em fazeção. Nesse sentido, vale a pergunta: de que modos existir desejante enquanto agente do chão? Como resistir desejante?

Reviso as Condições de Campo de Stan Allen: "fenômenos de baixo para cima, definidos não pelos esquemas geométricos abrangentes, mas por conexões locais intrincadas" (ALLEN, 2001, p. 2, tradução própria). Matrizes cujas formas gerais são fluidas e produtos provisórios de processos: importam menos que as relações internas das partes que, ao determinar o comportamento do campo, estabelecem as condições locais conformadoras de espaço. Nesse sentido, via agenciamentos do desejo entre corpo e chão, traço o plano: cidade enquanto meio que não para de se fazer.

Encontros, intensidades, desejo, processos, imanência, chão: corpo-campo experimentado; corpo-cidade em fazeção. No mesmo artigo, ao refletir sobre arquitetura e contexto urbano, Stan Allen repensa a relação entre figura e fundo. Aponto para o fato de que a expressão "figura e fundo" em inglês se escreve "figure and ground" - e que a palavra ground significa também chão. Com Allen, figuras passam a ser entendidas não enquanto objetos demarcados e lidos contra o fundo, mas como efeitos emergentes do campo em si, de suas intensidades.

Em atenção à produção de diferença que se dá em escalas locais, sugestão de Allen (2001, p. 7), é possível perceber políticas arquitetando o urbano. Figuras que emergem - ou imanam — das práticas do fundo; ações de chão. Como o $\mathrm{Ta}^{-}$ 
pete Voador ou o Campo de Tulipas em Park Fiction: quando a ficção dos desejos pouco a pouco, pedaço a pedaço, se materializa em espaço público.

Na relação entre urbanismos enquanto processos e políticas do chão, em um texto chamado Terra Fluxus, o arquiteto e teórico da paisagem James Corner conceitua sobre uma prática híbrida que traduzo aqui como Urbanismo de Paisagem, endereçando enquanto tema provisório os processos - de urbanização - ao longo do tempo. Muito mais significativos para a formação das relações urbanas que as formas espaciais do urbanismo em si, processos como globalização, acumulação de capital e proteção ambiental, fluiriam, se manifestariam e sustentariam, segundo Corner (2006, p. 28), as estruturas formais do urbano.

A sugestão do autor é, então, por deslocar a atenção das qualidades objetivas do espaço para os sistemas que condicionam a distribuição e densidade da forma urbana. Por exemplo: atentar aos preceitos modernistas, economia petrolífera, lógicas segregacionistas e especulações imobiliárias que conformam o tecido urbano da Barra da Tijuca; ou à espetacularização urbana, gentrificação, lutas sociais e ocupações que, em disputa, fizeram chão para Park Fiction em St. Pauli. Ao alertar que ordens espaciais não podem controlar história e processo, a partir do geógrafo David Harvey, o convite que Corner faz é a um olhar direto e ativo para os fluxos, forças e relações das cidades na concepção e construção urbanas. Entendimento de processos enquanto prática urbanística.

Penso, no entanto, numa atenção aos processos que não se descola das materialidades e que, inclusive, entende as coimplicações entre matéria e fluxo, debruçando-se sobre as coisas. Que busca considerar os efeitos dos efêmeros para além de suas durações - nos tangíveis conformados por políticas e delas conformadores. Uma atenção às coisas chãs. Como propõe Thiago Florêncio (2018, p. 64), etnógrafo e historiador, - o que aqui entendo enquanto possível procedimento de urbanismos imanentes e do chão: “operar pela imanência do terreno áspero e pela multiplicação de perspectivas singularizantes das materialidades, através das quais as coisas falam".

Fato é que as coisas chãs têm muito a dizer sobre processos de urbanização - mesmo aquelas soterradas por anos de práticas de cidade; mesmo aquelas removidas, desterradas; mesmo as que ainda virão. Em Terra Fluxus, Corner elabora outro tema do Urbanismo de Paisagem que muito me interessa e que concerne justamente à superfície horizontal, ao plano do chão, ao campo de ação: a "preparação de superfícies". Ao sugerir que o campo urbano é constituído por superfícies variadas - que, em uma ampla gama de escalas, vai das calçadas às ruas e à matriz infraestrutural completa de superfícies urbanas -, o texto estabelece um contínuo em que tetos e chãos se tornam um só campo de ação ou, como gosto de tensionar: um só plano de consistência composto por mil platôs de intensidade. Essa visão, ao borrar as separações usuais entre paisagem e edifícios, aponta também para um urbanismo que opera pela "irrigação de territórios com potencial” (KOOLHAAS apud CORNER, 2006, p. 30-31): semeia futuras possibilidades e, a partir de forças e relações atuantes no urbano, prepara o solo para novas atividades e padrões de ocupação.

Preparar o chão pelas políticas do chão. Pelas (an)danças que o constituem. Um chão de tropeços. Irregular. Repleto de toda sorte de coisa. Buscando reconhecer, portanto, que a cidade já é feita de cotidianos e efêmeros, me pergunto, enfim: como atentar a estas políticas e, então, trabalhar por uma espécie de urbanismo imanente e do chão - em contraposição à determinação de usos comumente realizada na arquitetura?

\section{Programa-Programa-Programa}

Desta pergunta e na chave dos usos predeterminados pela arquitetura e pelo urbanismo, proponho um breve ensaio sobre a palavra programa. Muito frequente no vocabulário de projetos, "programa", nesse contexto, se refere usualmente a um estabelecimento prévio de funções ou usos estanques para os espaços que se pretende trabalhar. Também denominado "programa de necessidades", reúne uma série de demandas ou propostas utilitárias e de atividades a serem abrigadas pelo projeto, podendo acompanhar metragens quadradas.

Programa: museu com cinco salas de exposição, setor administrativo, depósito, três banheiros, um café, uma lojinha. Programa: apartamento com dois quartos, uma suíte, um banheiro, sala de estar integrada à de jantar, uma cozinha. Programa: parque com área de descanso, de brinquedos para crianças, academia da terceira idade, ciclovias. Programa: zona urbana de uso misto, zona industrial, zona de residências unifamiliares, zona gastronômica e corporativa.

Radicalmente funcionalistas, esses programas norteiam e definem - mais que projetos - corpos, encontros e afetos.

Revista online do Departamento de Arquitetura e Urbanismo da 


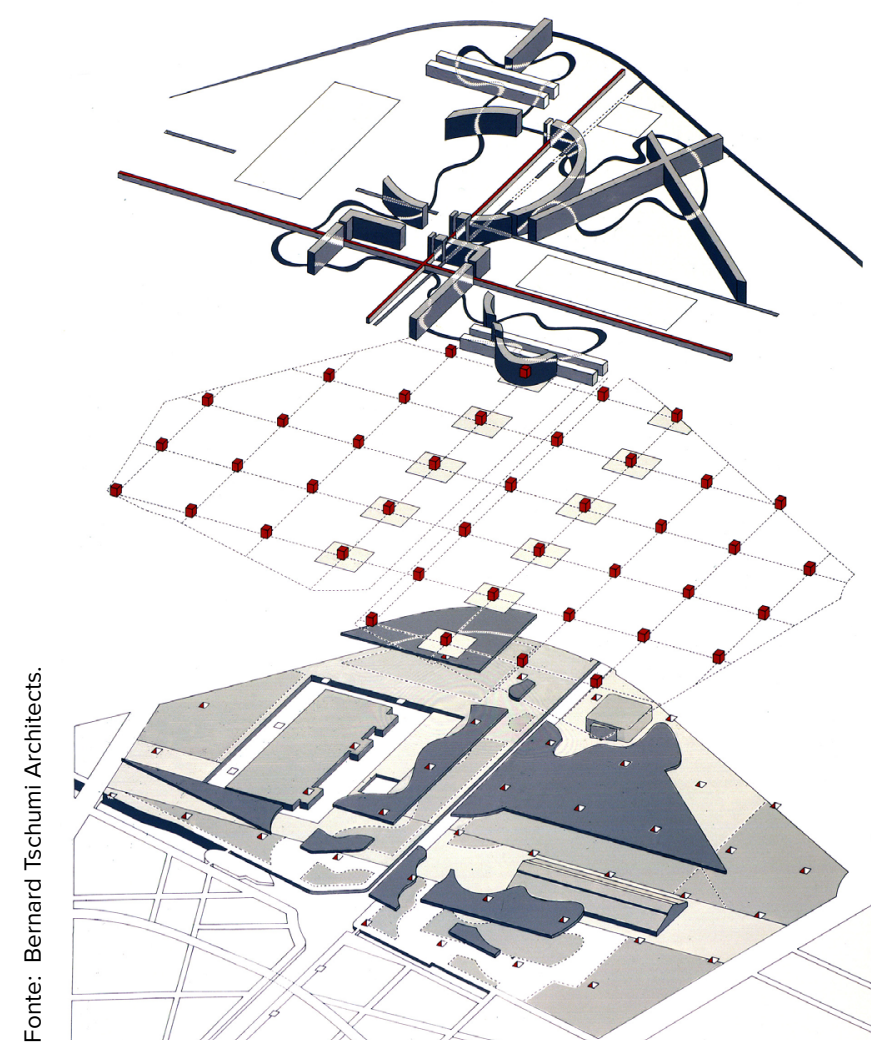

Figura 4. Parc de la Villette, Paris, 1982-1998.

Um programa que programa organismo e meio. Ao impor supostas soluções ou modos de agir nos espaços e disciplinar usos e circulações, o programa canaliza experiências e produz hábitos, gestos e subjetividades. E até você perceber que está reproduzindo um programa que não é seu - como apontou o performer e professor Caio Riscado em conversa ${ }^{12}$ sobre performance e cidade -, demora...

Há projetos, no entanto, que operam de outros $\operatorname{modos}^{13} \mathrm{e}$ buscam revisar a questão programática, garantindo maior liberdade aos ditos "usuários" ao propor estruturas de usos indeterminados. Um exemplo é o projeto do arquiteto Bernard Tschumi construído entre 1982 e 1998 - o Parc de la Villette.

Elaborado a partir de três sistemas ou camadas - superfícies, linhas (caminhos) e pontos (estruturas metálicas) - , o parque tem uma área de 55 hectares. A camada de pontos, que ordena o projeto em grande medida, se organiza por uma malha, ou grelha, ortogonal de aproximadamente 120 metros na qual se dispõem as chamadas folies (loucura em francês): ${ }^{14} 26$ edificações distintas, pintadas em vermelho, que resultam de variações formais de cubos de 10 metros de aresta. Não possuindo, em sua maioria, funções pré-determinadas, esses espaços abrigam programas informais,

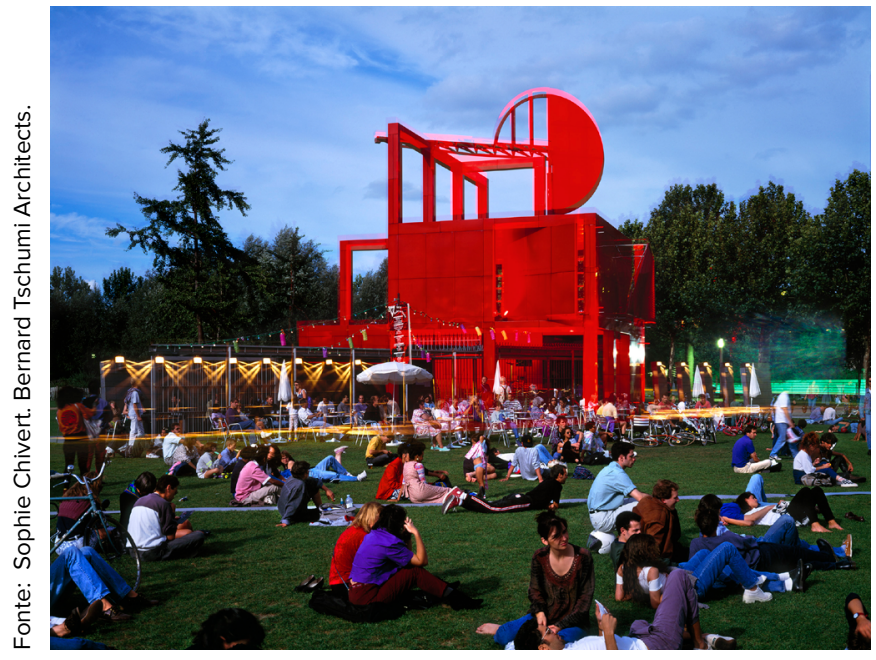

Figura 5. Parc de la Villette, Paris, 1994.

efêmeros e cambiantes, estabelecidos pelos corpos agentes do parque. Ainda que estejam todos cobertos de uma mesma tinta (monocromo vermelho que pontua o espaço e gera uma espécie de identidade visual), as diferenças formais e a abertura programática permitem atividades e interações diversas e uma maior determinação dos agentes estimulada pela indeterminação dos usos.

A operação formal abstrata do grid, sistema de grelha que caracteriza o campo, estende uma estrutura por toda a vasta superfície de modo a garantir um "desenvolvimento flexível e mutável” (CORNER, 2006, p. 31, tradução própria) da paisagem ao longo do tempo. A paisagem aqui, segundo o que projeto, engloba os processos, fluxos e corpos todos; incluindo as alterações formais que elaboram. Folies e rios de concreto, passos, falas e gestos enquanto elementos de paisagem. Ao operar por paradoxo, o grid de folies vermelhas, ao mesmo tempo em que ordena e torna legível a superfície, consente "autonomia e individualidade a cada parte" (CORNER, 2006, p. 61, tradução própria) - e a cada corpo que dela tome parte, possibilitando uma vasta gama de acomodações do, e no, campo.

E se o campo, como queria Stan Allen, é fundamentalmente um fenômeno horizontal de superfícies por vezes espessadas, penso o Parc de la Villette enquanto operação de campo pelo campo, que prepara chão e permite que ele se faça com o tempo: das fazeções de cidade e das intensidades que conferem dimensões outras aos planos.

De volta à questão dos programas, Tschumi opera, conforme descreve em seus desenhos, por uma "Desconstrução Programática" (Deconstruction Programmatique). ${ }^{15}$ Aten- 
dendo aos requisitos de atividades culturais, educacionais, esportivas e de lazer do concurso internacional que vence em 1982, o arquiteto opta por distribuir as demandas pelo terreno e propor edificações abertas às definições que se queira dar na ação desses espaços. Desse modo, agencia um programa de indeterminação parcial que foge dos padrões de uma mercado-lógica (sempre seguidos por programas funcionais): um reprograma. No parque, a repartição do programa de base (áreas construídas, cobertas e ao ar livre) é explodida diagramaticamente sobre o terreno e, então, recomposta em pontos distribuídos pela grade. Se algumas folies têm função (restaurante, café, posto de primeiros socorros), outras muitas não. Instauram-se essas estruturas, portanto, como o maior denominador comum da desconstrução proposta: o programa em ação.

Como aposta destas linhas e caminhos que venho construindo, gostaria de pensar uma outra possibilidade de programa em arquitetura e, especialmente, urbanismo. Nem o programa do uso que determina o espaço, nem a desconstrução programática do espaço que abriga a indeterminação dos usos. Entre resistência e aderência, determinação e indeterminação - um outro programa: o programa performativo enquanto prática projetual.

Intencionando operar por modos de existência imanentes - portanto, atentos à materialidade das coisas - e não previamente determinados, que disparem afetos outros e trabalhem por lógicas distintas das de mercado, função e reprogramação via indeterminação parcial de usos, me pergunto sobre a possibilidade de agenciar o "programa performativo", conceito de Eleonora Fabião, em substituição a e em subversão dos arquitetônicos e urbanísticos determinantes. Definido pela professora, performer e teórica da performance a partir do texto 28 de novembro de 1947 - Como Criar Para Si Um Corpo Sem Órgãos, de Deleuze e Guattari (2012b), o programa performativo é o "motor da experimentação enunciado [da performance] que norteia, move e possibilita a experiência" (FABIÃO, 2013, p. 1).

Programa: "Sentar numa cadeira, pés descalços, diante de outra cadeira vazia (cadeiras de minha cozinha). Escrever numa grande folha de papel: CONVERSO SOBRE QUALQUER ASSUNTO. Exibir o chamado e esperar.” (FABIÃO, 2015, p. 12); Programa: "Cobrir com tapetes vermelhos caminhos percursos marcados pelo caminhar de corpos em solo urbano" (CABRAL, 2018, p. 71); Programa: "Um grupo de brasilei- ros, vestindo camisas com as inscrições 2016 (frente) e 1964 (costas), caminha lentamente, silenciosamente e de costas pelas ruas com as mãos espalmadas para baixo. Os pontos de início e término da caminhada são preestabelecidos em consonância a fatos históricos" (ELILSON, 2017, p. 25).

Vale notar que as práticas de programas performativos não são quaisquer; têm como potência "des-habituar, des-mecanizar, escovar à contra-pêlo” (FABIÃO, 2008, p. 237) - vetores disparados pelos exemplos acima. Desse modo, ações programadas em performance lidam com mundos por vias alternativas, visibilizando lógicas e sistemas estabelecidos, resistindo a eles, correndo por suas margens, rompendo-os ou os ignorando completa e intencionalmente. Criam, assim, situações de dissenso e dissonância nas mais diversas ordens: "econômica, emocional, biológica, ideológica, psicológica, espiritual, identitária, sexual, política, estética, social, racial..." (FABIÃO, 2008, p. 237). (Des)programam. ${ }^{17}$

Ao reunir as "ações previamente estipuladas, claramente articuladas e conceitualmente polidas" a serem realizadas sem ensaio prévio, Fabião propõe que "quanto mais claro e conciso for o enunciado-sem adjetivos e com verbos no infinitivo-mais fluida será a experimentação", de modo a garantir "precisão e flexibilidade" (FABIÃO, 2013, p. 4). Nesse sentido, poderíamos aproximar o programa performativo de uma estrutura ou grid a partir da qual encontros, agenciamentos, negociações e circulações afetivas outras serão deflagrados.

Ainda segundo a artista, o programa é um "procedimento composicional específico" (FABIÃO, 2013, p. 4) através do qual suspendem-se automatismos e hábitos - resistindo à passividade do pertencimento e ao torpor das aderências. As performances, colocadas a partir de programas e enquanto “composições atípicas”, são também "práticas de negociação e de criação de corpo” (FABIÃO, 2008, p. 245) - aqui e agora. Fazem corpo-cidade na medida em que são agidas.

A execução dos programas constrói, desse modo e de fato, espaço. Compõe espaçocorpo a realização de enunciações elaboradas contextual e, portanto, politicamente. Isso porque, importa lembrar, tais enunciados ou iniciativas devem ser inventados a cada vez, de modo a condizer com as questões em pauta e aderir aos contextos vigentes (FABIÃO, 2013, p. 5 e 10). Como as políticas do chão, como os agenciamentos do desejo, como as preparações de um território que consideram os efêmeros, cotidianos. Dessas ideias me pergunto, ainda sem qualquer resposta, mas como quem se

Revista online do Departamento de Arquitetura e Urbanismo da 
lança a experimentações: como pensar urbanismos agenciados por procedimentos composicionais frasais, contextuais e, portanto, políticos, que conformam situações dissensuais — tão fundamentais ao espaço urbano?

O programa performativo, enquanto prática urbanística que aqui proponho, operaria pela imanência do plano de consistência da cidade. Pelos desejos e pelo dissenso. Fazendo corpo com. Fato é que o programa performativo é da ordem da construção. Da ordem da ação. E do fazer. Implica uma fazeção de corpo todo - não mais e apenas dos braços para cima; prática usual em escritórios e escolas de arquitetura e urbanismo que debruçam corpos humanos sobre mesas, mapas e papéis, delimitando projeto a membros superiores e cabeças distantes das ruas.

Ressalto que convoco o programa aqui não como método de levantamento, mas enquanto prática efetiva de projeto urbano: de negociação e composição, a cada vez, de corpo-cidade; de desprogramação de corpo e meio; de criação de "situações políticas" que desautomatizam e turbinam a "relação do cidadão com a pólis" (FABIÃO, 2008, p. 237); de construção de cidades que se descrevem mais em termos de encontros, velocidades e potências que de formas e funções. O programa performativo, enfim, enquanto operador de um urbanismo imanente, do chão.

\section{Notas de fim:}

1. Ver mais em Stan Allen (2001. p.7) e em ELVIRA, Juan. Formworks. Murado \& Elvira - Architecture. Disponível em: https://muradoelvira. com/formworks. Acesso em: 29, jul. 2019.

2. Seu caráter processual e imprevisível, já que quem age o faz no aqui e agora, sem saber com precisão das consequências.

3. Pela lateral de uma série de condomínios fechados (o que habito há 10 anos incluso), conectando duas importantes avenidas da Barra da Tijuca, passam duas pontes que têm o nome dos mais famosos arquitetos modernistas do país - vias de alta velocidade ladeadas por estreitas calçadas sem conexão. A impossibilidade de travessia segura/sinalizada é situação corriqueira no bairro.

4. Giuliana Almasio (que, praticamente sem me conhecer, descalçou sapatos e dobrou espinha para entapetar caminhos) e André Porto (a quem agradeço pelas imagens aéreas e solidárias mãos na terra). Além dessas, outras quatro mãos foram fundamentais para que a obra acontecesse - as de minha mãe e de meu pai que, na noite anterior, cortaram comigo os panos.

5. Sociedade dos Amigos da Rua da Carioca e Adjacências, tradicional mercado popular a céu aberto no centro do Rio.

6. O Plano Piloto de Brasília (1957), também projetado por Lucio Costa e bastante pensado para a circulação de automóveis, é repleto de caminhos de rato: atalhos e percursos traçados por pés.
7. Faço esse adendo inspirada em uma nota de Paola Berenstein Jacques que, em sua tese para professora titular, escolhe traduzir o Town Planning de Patrick Gueddes como urbanismo, afirmando que "as palavras não são neutras e mudam de significado ao longo do tempo [...] mas, em nossa defesa da ampliação do campo do urbanismo, nos parece importante manter essa terminologia" (JACQUES, 2018, p. 48).

8. O termo "viaturas da nova cidade" remete a Carvalho (2016).

\section{Ver: Park Fiction (2013).}

10. "Tanto nas ciências nômades como nas ciências regias, encontraremos a existência de um 'plano', mas que de modo algum é o mesmo. Ao plano traçado diretamente sobre o solo do companheiro gótico opõe-se o plano métrico traçado sobre papel do arquiteto fora do canteiro. Ao plano de consistência ou de composição opõe-se um outro plano, que é de organização e de formação. Ao talhe das pedras por esquadrejamento opõe-se o talhe por painéis, que implica a ereção de um modelo a reproduzir" (DELEUZE e GUATTARI, 2012a, p. 36).

11. "[...] a experimentação como operação sobre este plano [de consistência]” (DELEUZE e GUATTARI, 2012b, p. 25).

12. Essa conversa teve lugar no curso Performance e Arquitetura, ministrado pelos professores Caio Riscado e Yuri Quevedo em julho de 2019 na Escola da Cidade (SP).

13. Tema desenvolvido em: CABRAL, Bárbara Silva da Veiga URBANISMOS DO CHÃO: o programa performativo nas fazeções urbanas. Orientação: Elizabeth Jacob; Caio Riscado. Dissertação (Mestrado em Artes da Cena) - Escola de Comunicação, Universidade Federal do Rio de Janeiro, Rio de Janeiro, 2021. Na primeira parte da dissertação, trabalho alguns modos de operação do conceito programa para além da abordagem funcional brevemente descrita aqui - modos de operação percebidos por meio de diferentes acontecimentos em arquitetura e urbanismo, em aposta à ideia de Penelope Dean (2006, p. 49) de que mais vale perguntar o que o programa "pode fazer" que buscar definir o que o programa é. Já na segunda parte do texto, sugiro a elaboração e ação de "programas performativos" (FABIÃO, 2008) como práticas de projeto e fazeção urbanos, propondo urbanismos performativos, da ação e do chão ao pensar práticas artísticas minhas, como TECIDO-NÃO-TECIDO, e de outras pessoas, Rio de Janeiro, 2021.

14. Carlos Gonçalves Terra (1993, p. 6) destaca que o termo francês folie "denomina o monumento arquitetônico situado em um jardim e caracterizado por um certo grau de excentricidade ou inutilidade manifesta". O autor aponta ainda que a palavra correspondente em inglês é folly e também se refere à loucura.

15. Ver mais em: PARC DE LA VILLETTE. Bernard Tschumi Architects. Disponível em: http://www.tschumi.com/projects/3/\#. Acesso em: 29, jun. 2021 Para visualizar o diagrama de Desconstrução Programática, acessar: PARC DE LA VILLETTE, 1983-1992. FRAC Centre - Val de Loire. Disponível em: https://bit.ly/2OoQkRZ. Acesso em: 29, jun. 2021.

16. "O performer não improvisa uma ideia: ele cria um programa e programa-se para realizá-lo [...]. Ao agir seu programa, desprograma organismo e meio" (FABIÃO, 2008, p. 237). 


\section{Referências Bibliográficas:}

ALLEN, Stan. Field Conditions. In: Points + Lines: 1985 . New York: Princeton Architectural Press, 2001, p. 90-137.

ARENDT, Hannah. A Condição Humana. 10. ed. Rio de Janeiro: Editora Forense Universitária, 2007.

CABRAL, Bárbara Silva da Veiga. afetos: filosofia e arte nas interações corpo-cidade. Trabalho de Conclusão de Curso (Arquitetura e Urbanismo) - Departamento de Arquitetura e urbanismo, Pontifícia Universidade Católica do Rio de Janeiro, Rio de Janeiro, 2018.

CARTER, Paul. The Lie of the Land. London: Faber and Faber, 1996.

CARVALHO, Ernesto de. Nunca é noite no mapa / It's never nighttime in the map. Recife, Brasil, 2016. Disponível em: https://vimeo .com/175423925. Acesso em: 2, set. 2021.

CORNER, James. Terra Fluxus. In: WALDHEIM, C. (Ed.). The Landscape Urbanism Reader. New York: Princeton Architectural Press, 2006.

DEAN, Penelope. Program Is as Program Does. PRAXIS: Journal of Writing + Building, n. 8, p. 48-51, 2006.

DELEUZE, Gilles. Espinosa: filosofia prática. Tradução: Daniel Lins e Fabien Pascal Lins. São Paulo: Editora Escuta, 2002.

DELEUZE, Gilles; GUATTARI, Félix. 1227 - Tratado de nomadologia: a máquina de guerra. In: . Mil Platôs. Capitalismo e Esquizofre-

nia - v. 5, Rio de Janeiro: Editora 34, 2012a. p. 11-118.

. 28 de novembro de 1947 - Como Criar Para Si Um Corpo Sem Órgãos. In:__. Mil Platôs. Capitalismo e Esquizofrenia - v. 3, Rio de Janeiro: Editora 34, 2012b. p. 11-34.

ELILSON. Por uma mobilidade performativa. 2. ed. Rio de Janeiro: Editora Temporária, 2017.

FABIÃO, Eleonora. Performance e teatro: poéticas e políticas da cena contemporânea. Sala Preta, v. 8, p. 235-246, 2008.

. Programa performativo: o corpo-em-experiência. ILINX - $R e$ vista do LUME, v. 1, n. 4, p. 1-11, 2013.

Ações: Eleonora Fabião. Organização: Eleonora Fabião, André Lepecki. Rio de Janeiro: Tamanduá Arte, 2015.

FLORÊNCIO, Thiago. Nativo ausente e escrita-despacho. Vazantes, v. 02, p. 61-70, 2018.

JACQUES, Paola Berenstein. Zonas de Tensão: em busca de micro-resistências urbanas. In: BRITTO, Fabiana Dutra; JACQUES, Paola Berenstein (Org.). Corpocidade: debates, ações e articulações. Salvador: EDUFBA, 2009, p. 106-119.

. MONTAGEM DE UMA OUTRA HERANÇA: urbanismo, memória e alteridade. Salvador: Universidade Federal da Bahia, 2018.

LEFEBVRE, Henri. O direito à cidade. Tradução: Rubens Eduardo Frias. 5. ed. São Paulo: Centauro, 2011.

LEPECKI, André. Coreopolítica e Coreopolícia. Ilha Revista de Antropologia, Florianópolis, v. 13, n. 1,2, p. 41-6o, 2012.
PARK FICTION - Introduction in English Park Fiction, 2013. Disponível em: http://park-fiction.net/park-fiction-introduction-in -english/. Acesso em: 9, jun. 2021.

SCHÄFER, Paul. The City is Unwritten - urban experiences and thoughts seen through Park Fiction. Park Fiction, 2004. Disponível em: https://park-fiction.net/the-city-is-unwritten-urban-experiences -and-thoughts-seen-through-park-fiction/. Acesso em: 13, jul. 2021.

TERRA, Carlos Gonçalves. Os Jardins no Brasil do Século XIX: Glaziou revisitado. [S.1.]: Universidade Federal do Rio de Janeiro, 1993. 